\title{
樹木の熱・水分・二酸化炭素収支のモデル化に関する考察 \\ MODELING THE BUDGETS OF HEAT, WATER VAPOR, AND CARBON DIOXIDE WITHIN A TREE
}

\author{
平岡 久司* \\ Hisashi HIRAOKA
}

\begin{abstract}
Modeling the balances of heat, water. vapor, and carbon dioxide within three-dimensional vegetation was tried. This model consists of three submodels: a model for turbulent flow within vegetation, a model for radiation transfer within vegetation, and a stomatal conductance model. This model was applied to a single tree. The numerical experiment resulted in the following:

1) A great deal of short wave radiation absorbed by leaves was released through transpiration.

2) The influence of long wave radiation on the energy balance within the tree was not negligible.

3) The sensible heat transfer due to water vapor flux from leaves hardly affected the energy balance within the tree. The fact indicates that the results from the turbulence model for dry air are almost equal to those of the turbulence model for moist air.
\end{abstract}

Key words : vegetation, turbulence model, radiation transfer model, stomatal conductance model

植栽，乱流モデル，放射輸送モデル，気孔コンダクタンスモデル

\section{1.はじめに}

植物は人の心を和ませたり、建物や都市の美観といった視覚的心 理的効果だけでなく、熱・空気環境の改善にも大きな潜在的力を持 っている。例えば、部屋の中に置かれた植物は、臭気を消したり、 二酸化炭素を吸収し酸素を放出することにより空気を浄化する。ま た、家の周りに植えられた落葉樹は、住居の熱環境に大きな効果を もたらす。夏は太陽日射を遮蔽し、家の壁や空に入る日射量を大幅 に減少させ、夏の暑さの緩和や冷房負荷の軽減といった省エネルギ 一効果をもたらす。1枚の葉は入射する日射エネルギーの約半分を 吸収する。冷房負荷を考えるとき、樹木は大きな省エネルギー効果 を持っている。ビルにおいても、外壁に蔦を這わせると、壁面に入 射する日射量を激減させる。また、葉の蒸散作用により葉面は上昇 せず、葉からの長波放射の射出量は増大しない。このように葉は入 射した日射を顕熱に変換することなく、壁面に入射する日射量を減 少させる。屋上に植栽することも省エネルギー効果をもたらす。植 生による日射量の減少効果だけでなく、根による保水効果により、 長期間に渡る蒸発散によって屋上面の温度上昇を和らげ、屋上から 室への流入熱を減少させるのを可能にする。植物は建物の熱環境を 考えたとき、大きな省エネルギー効果を潜在的に持っている。次に、 都市の緑地や公園を取り上げてみる。緑地は都市部の中のクールス
ポットになっており、市街地部に比べて低温になっていることが観 測から明らかになっている。都市内に緑地を適切に配置することに よって、都市の気温上昇を緩和することが期待できる。また、植物 は二酸化炭素を吸収し、酸素を放出するため、都市の空気を净化す る作用も持っている。森林や水田に目を向けると、植栽が地球の温 暖化の抑制に大きな役割を持っていることが分かる。植物の二酸化 炭素固定作用によって、人間活動により排出された二酸化炭素を吸 収し、大気の二酸化炭素濃度の上昇を抑制する。植物と海洋は二酸 化炭素の巨大な吸収源であり、地球温暖化を抑制する役割は大きい と考えられる。

以上のように、植栽は見た目の心地良さといった視覚的心理的な 面だけでなく、熱環境面にも重要な役割を果たす。これらのことは、 観測や体験から定性的には分ってるが、定量的な取り扱いはまだ不 十分な状況である。植栽の熱・水分収支モデルを作成することによ り定量的な取り扱いが可能になる。以上に述べたような背景から、 我々は植栽の熱・水分・五酸化炭素収支のモデル化を検討している。 この研究の目的は、一本の樹木を対象として、植栽の熱·水分·二 酸化炭素収支のモデル化を行うことである。樹木は 3 次元形態をし ており、モデル化の点からは最も難しい。3 次元の樹木のモデル化 が可能になれば、森林などの1次元場と見做せる植生のモデル化は、

$*$ 京都大学工学研究科環境地球工学尃政 助手 $\cdot$ 博士 (工学)

Research Assoc., Div. Global Environment Engineering, Graduate School of Engineering, Kyoto University, Dr. Eng. 
3次元モデルの解法の近似化あるいはモデルの一部を実験式に置き 換えることにより簡易化される。その意味で、ここで取り上げた 3 次元植栽のモデル化は重要と考える。

本研究では、植栽内の熱・水分・二酸化炭素収支モデルを作成し、 そのモデルを樹木に適用し、葉群内の熱・水分・二酸化炭素収支の 計算を行った。今回報告するモデルは 3 つのサブモデルからなる。 即ち、植栽内の乱流モデル、植栽内の放射輸送モデル、そして気孔 コンダクタンスモデルである。植栽内の乱流モデルは我々が提案し たモデルを用いた。植栽内の放射輸送モデルに関してはR Ross のモデ ルを用いた。気孔コンダクタンスモデルについては Collatz らのモデ ルを用いた。このモデルの特徴の 1 つは、乱流モデルと Ross の放射 輸送モデルを使用しているため、1 次元から 3 次元までの植栽の 熱・水分収支を予測できることである。もう1つの特徵は、気孔コ ンダクタンスに影響を及ほす環境因子間の相互作用を組み込んだ気 孔コンダクタンスモデルを使用したことである。次の節で、この研 究で使用したサブモデルの説明を行う。

\section{2. モデルの詳細}

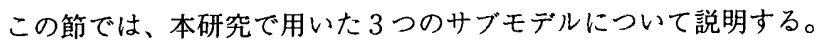

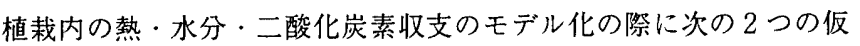
定を用いた。第1の仮定は、植物は土塞から十分な水分を供給され ているため、葉の水ポテンシャルは気孔の開閉に影響しない。第 2 の仮定は、単一葉の放射特性は Lambertian タイプと仮定する、即ち、 単一葉の放射特性は葉の透過率、反射率、そして射出率によって決 定される。第1の仮定は、この研究で採用した気孔コンダクタンス モデルの使用に必要である。第2 の仮定は、Ross の放射輸送モデル を拡散近似によって計算する際に必要である。

Table 1 にこの研究で用いた植栽内の湿潤空気の乱流モデルを示す。 この乱流モデルは、前報 $11 ２$ 2)、3 で示した乱流モデルのモデル化の 方法に従って、気温、比湿、二酸化炭素濃度の式を含むように修正 した。(1)式（連続の式）の導出に関しては[Appendix-1]参照。(3)式 （湿潤空気の平均温度方程式）の導出に関しては[Appendix-2]参照。 (1)式内の $S_{v a p}$ 項は蒸散による水蒸気のソース項を示す。 $S_{\mathrm{CO}_{2}}$ と $S_{O 2}$ 項は光合成によるシンク項とソース項を示す。 $S_{v a p}$ のオーダー

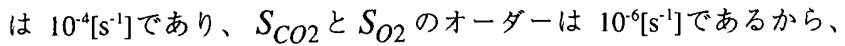
$S_{\mathrm{CO} 2}$ と $S_{\mathrm{O} 2}$ 項は省略できる。(3)式内の $H_{v a p}$ 項は蒸散による水蒸 気の葉面からの流出による顕熱を示す。蒸散による潜熱は湿潤空気 の温度方程式には表れない。このことは、蒸散による潜熱は葉を冷 却するが、周囲空気の温度変化には影響を及はさないことを示す ([Appendix-2]参照)。(3)式の $\mathrm{H}_{\mathrm{CO} 2}$ と $\mathrm{H}_{\mathrm{O} 2}$ 項は光合成による周囲

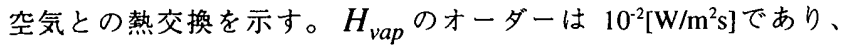
$\mathrm{H}_{\mathrm{CO} 2}$ と $\mathrm{H}_{\mathrm{O} 2}$ のオーダーは $10^{-4}\left[\mathrm{~W} / \mathrm{m}^{2} \mathrm{~s}\right]$ であるから、 $\mathrm{H}_{\mathrm{CO} 2}$ と $H_{\mathrm{O} 2}$ は省略できる。以後、計算に於ては、 $S_{\mathrm{CO} 2} 、 S_{\mathrm{O} 2} 、 \mathrm{H}_{\mathrm{CO} 2} 、 \mathrm{H}_{\mathrm{O} 2}$ 項は省略する。

葉面での熱・水分·二酸化炭素の釣り合い式を Table 2 に示す。葉 と空気との熱交換を計算するためには植栽内の放射量を知る必要が ある。Table 2(1)式内の 3 種の放射量 $\left(Q_{P A R} 、 Q_{N I R}\right.$ と $\left.R_{n e t}\right)$ を計 算するために、本研究では Ross の放射モデル41，5を用いた。ここ で、添え字 PAR は Photosynthetically Active Radiationを示す。添え字 NIR は Near InfraRed radiationを示す。 3 種の放射量（ $Q_{P A R}$ 、
[Table 1] Turbulence model for moist air used in this study

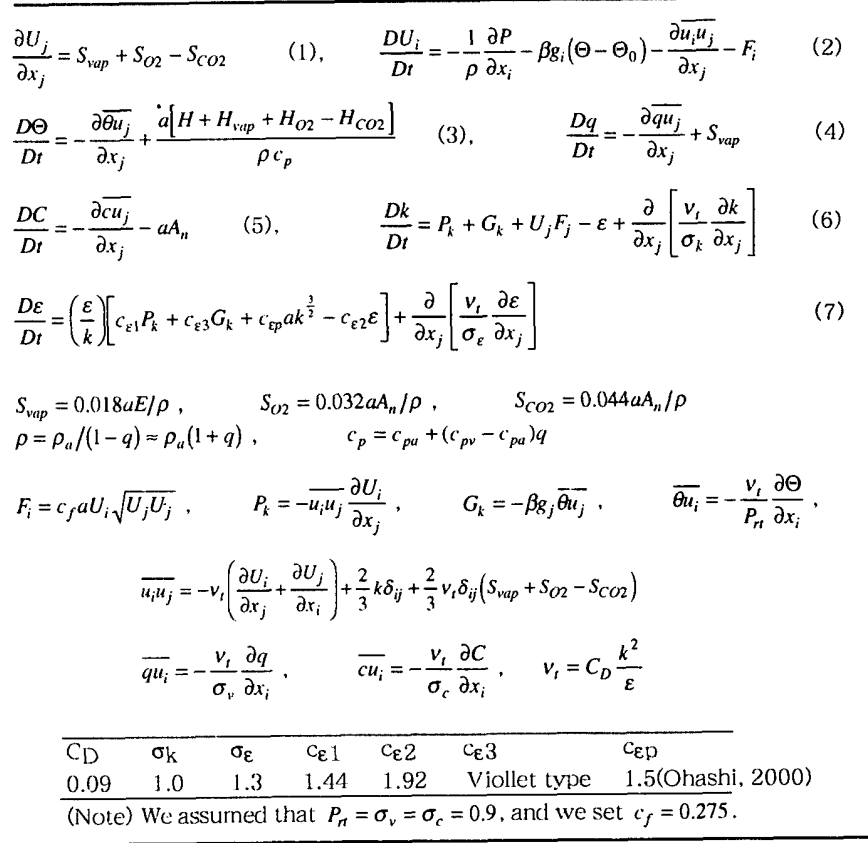

[Table 2] The balances of heat, water vapor, and $\mathrm{CO}_{2}$ on leaves (a) Heat exhange between ambient air and leaves

$a\left(Q_{P A R}+Q_{N I R}+R_{n e t}\right)=a\left(H+l_{v} E+H_{v a p}+H_{O 2}-H_{C O 2}\right) \quad(1), \quad H=2 h_{c}\left(T_{t}-\Theta\right)$

$H_{\text {vap }}=C_{p}^{v a p}\left(T_{l}-\Theta\right) E \quad(3), \quad H_{O 2}=C_{p}^{O 2}\left(T_{l}-\Theta\right) A_{n} \quad(4), \quad H_{C O 2}=C_{p}^{C O 2}\left(T_{l}-\Theta\right) A_{n}$

(b) Water vapor flux

$E=g_{s}\left(\frac{e_{s}\left(T_{i}\right)}{P_{0}}-c_{s}^{\text {vapor }}\right)=\alpha_{v} \frac{P_{0}}{R(\Theta+273.15)}\left(c_{s}^{\text {vapar }}-c_{a}^{\text {vapor }}\right) \quad$ (6). $\quad c_{a}^{\text {vapor }} \approx q / 0.622$

(c) Photosynthetic rate

$A_{n}=\alpha_{c} \frac{P_{0}}{R(\Theta+.273 .15)}\left(c_{a}^{C O 2}-c_{s}^{C O 2}\right)=\frac{g_{s}}{1.6}\left(c_{s}^{C O 2}-c_{i}^{C O 2}\right) \quad(7), \quad c_{a}^{C O 2}=C \frac{R(\Theta+273.15)}{P_{0}}$ W'c assumed that $\alpha_{v}=\alpha_{c}=h_{c} /\left(\rho_{a} c_{p u}\right)$, and $h_{c}=6.79+5.99 u$, (Daudet et al.. 1998).

[Table 3] Ross's radiation transfer equation used in this study (a) Short wave radiation

$i(\mathbf{x}, \mathbf{r})=i_{d}(\mathbf{x}, \mathbf{r})+I(\mathbf{x}, \mathbf{r}) \quad(1), \quad r_{j} \frac{\partial i_{d}(\mathbf{x}, \mathbf{r})}{\partial x_{j}}=-a(\mathbf{x}) G(\mathbf{x}, \mathbf{r}) i_{d}(\mathbf{x}, \mathbf{r})$

$r_{j} \frac{\partial l(\mathbf{x}, \mathbf{r})}{\partial x_{j}}=-a(\mathbf{x}) G(\mathbf{x}, \mathbf{r}) l(\mathbf{x}, \mathbf{r})+a(\mathbf{x}) \underset{\omega^{\prime}=4 \pi}{\int} \Gamma\left(\mathbf{x}, \mathbf{r}, \mathbf{r}^{\prime}\right) l\left(\mathbf{x}, \mathbf{r}^{\prime}\right) d \omega^{\prime}+a(\mathbf{x}) e(\mathbf{x}, \mathbf{r})$

$e(\mathbf{x}, \mathbf{r})=\int_{\omega^{\prime}=4 \pi} \Gamma\left(\mathbf{x}, \mathbf{r}, \mathbf{r}^{\prime}\right) i_{d}\left(\mathbf{x}, \mathbf{r}^{\prime}\right) d \omega^{\prime} \quad(4), \quad G(\mathbf{x}, \mathbf{r})=\frac{1}{2 \pi} \int_{\omega_{L}=2 \pi} g\left(\mathbf{x}, \mathbf{r}_{L}\right) \mid\left(\mathbf{r} \cdot \mathbf{r}_{L}\right) d d \omega_{L}$

$$
\begin{array}{r}
\Gamma\left(\mathbf{x}, \mathbf{r}, \mathbf{r}^{\prime}\right)=\frac{T(\mathbf{x})}{\pi} \Gamma_{T}\left(\mathbf{x}, \mathbf{r}, \mathbf{r}^{\prime}\right)+\frac{R(\mathbf{x})}{\pi} \Gamma_{R}\left(\mathbf{x}, \mathbf{r}, \mathbf{r}^{\prime}\right) \\
r_{T}\left(\mathbf{x}, \mathbf{r}, \mathbf{r}^{\prime}\right)=\frac{1}{2 \pi} \int_{\omega_{L}=2 \pi} g\left(\mathbf{x}, \mathbf{r}_{L}\right) H\left[\left(\mathbf{r} \cdot \mathbf{r}_{L}\right)\left(\mathbf{r}^{\prime} \cdot \mathbf{r}_{L}\right)\right] d \omega_{L} \\
\Gamma_{R}\left(\mathbf{x}, \mathbf{r}, \mathbf{r}^{\prime}\right)=\frac{1}{2 \pi} \int_{\omega_{L}=2 \pi} g\left(\mathbf{x}, \mathbf{r}_{L}\right) H\left[-\left(\mathbf{r} \cdot \mathbf{r}_{L}\right)\left(\mathbf{r}^{\prime} \cdot \mathbf{r}_{L}\right)\right] d \omega_{L} \\
H[f]=f \text { if } f \geq 0, \quad H[f]=0 \text { if } f<0
\end{array}
$$

(b) Long wave radiation

$r_{j} \frac{\partial i(\mathbf{x}, \mathbf{r})}{\partial x_{j}}=-a(\mathbf{x}) G(\mathbf{x}, \mathbf{r}) i(\mathbf{x}, \mathbf{r})+\frac{1-\varepsilon(\mathbf{x})}{\pi} a(\mathbf{x}) \underset{\omega^{\prime}=4 \pi}{\int} \Gamma_{R}\left(\mathbf{x}, \mathbf{r}, \mathbf{r}^{\prime}\right) i\left(\mathbf{x}, \mathbf{r}^{\prime}\right) d \omega^{\prime}+a(\mathbf{x}) e(\mathbf{x}, \mathbf{r})$

$e(\mathbf{x}, \mathbf{r})=\frac{\varepsilon(\mathbf{x})}{\pi} G(\mathbf{x}, \mathbf{r}) \sigma\left(T_{l}(\mathbf{x})+273.15\right)^{4} \quad(6), \quad \frac{1}{2 \pi} \int_{\omega_{L}=2 \pi} g\left(\mathbf{x}, \mathbf{r}_{L}\right) d \omega_{L}=1$ 
$Q_{N I R}$ と $R_{n e t}$ ) は次式で与えられる。

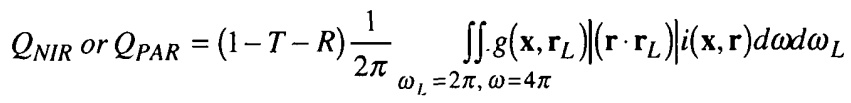

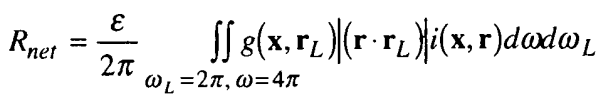

$-2 \varepsilon \sigma\left(T_{l}+273.15\right)^{4}$

放射輝度（i）はRoss の植物群落内放射輸送モデルから計算される。

Ross の植物群落内放射輸送モデルを Table 3 に示す。Ross のモデ ルでは単一葉の散乱特性は規定されていない。しかし、この論文で は、短波放射に関する葉群の散乱関数は単一葉の透過率と反射率を 用いて表している。長波放射の散乱関数は単一葉の射出率で表して いる。この理由は、Ross のモデルを拡散近似解法（Table 6, 7) で解 くためである。

Table 4, 5 に Collatz らの気孔コンダクタンスモデル6)を示す。彼 らのモデルでは、Ball の気孔コンダクタンス実験式7)（Table 4 (1) 式）、正味の二酸化炭素固定速度の式（Table 4 (2)式、また、係数 1.6 は水蒸気と二酸化炭素の拡散係数の比)、そして $\mathrm{C}_{3}$ 植物の光合成モ デル(Table 4(3)式)が組み合わされている。彼らの $\mathrm{C}_{3}$ 植物の光合成モ デルは Farquhar らのモデル8)を簡易化したものである。Collatz ら の光合成モデルかを Table 5 に示す。Collatz らの気孔コンダクタン スモデルでは、葉表面の相対湿度、葉表面の二酸化炭素濃度、そし て葉温を既知と仮定して: 気孔コンダクタンス、正味二酸化炭素固 定速度、そして細胞内の二酸化炭素濃度を計算する。本研究では、 葉表面の相对湿度、葉表面の二酸化炭素濃度、そして葉温を Table 2 に示与葉面でのフラックスの収支式と組み合わしている。

\section{3. 計算結果}

\section{1 計算の概要}

この研究では、1辺が $6 \mathrm{~m}$ 立方の樹木を取り上げた。計算領域は $48 \mathrm{~m}$ ( $\mathrm{x}$ 軸 $) \times 30 \mathrm{~m}$ ( $\mathrm{y}$ 軸 $) \times 30 \mathrm{~m}(\mathrm{z}$ 軸 $)$ とした。点 $(15 \mathrm{~m}, 15 \mathrm{~m}, 7 \mathrm{~m})$ を樹木葉群の中心とした。計算領域は $43 \times 34 \times 34$ 個のグリッドに 分割した。葉面積密度は $1\left[\mathrm{~m}^{2} / \mathrm{m}^{3}\right]$ とした法11。

上記に示した 3 つのサブモデルを結合させることによって、樹木 内の熱・水分・二酸化炭素収支を計算した。Table 1 に示した乱流モ デルは差分法（SMAC、Adams-Bashforth Scheme、QUICK 空間差分） で計算した。Table 1 (7)式内の係数 $c_{\text {\&p }}$ に関しては、大橋ら9)によっ て最適化された値（1.5）を採用した。

短波放射の計算に関しては、放射輝度の間接成分を拡散近似法に より計算した。拡散近似法では精緻解法に比べ、計算機の cpu 時間、 メモリ共に大幅に節約できる。短波放射の計算は、乱流モデルの計 算とは別個に求められる。長波放射に関しては、放射輝度の方程式 (Table 3(5)式) が直接に搪散近似法によって解かれた。Table 2 の葉 面での熱・水分·二酸化炭素収支式、気孔コンダクタンスモデル、 そして長波放射の式（拡散近似式）は乱流モデルのプログラムの中 に組み込まれた。Table 6（短波放射）と Table 7 (長波放射) に、拡 散近似式を示す。拡散近似に関しでは、文献 101.11 参照。この研 究での搪散近似式は、第 2 節で述べた第 2 の仮定を用い、Table 3 に 示す Ross の放射輸送方程式から導出した注 $21 。$ Table 6 と7・のポアソ ン方程式は、双 1 次線形補間関数を用いた Galerkin 有限要素法によ
[Table 4] Stomatal conductance model by Collatz et al. (1991)

\begin{tabular}{ll}
$g_{s}=m \frac{h_{s} A_{n}}{c_{s}}+b$ & $(1), \quad A_{n}=\frac{g_{s}}{1.6}\left(c_{s}-c_{i}\right)$ \\
$A_{n}=f\left(Q_{P_{A}}, T_{l}, c_{i}\right)$ & (3) $\quad:$ Photosynthesis model by Farquhar et al. (1980) \\
& This is simplified by Collatz et al. (1991). \\
\hline
\end{tabular}

[Table 5] Photosynthesis model simplified by Collatz et al. (1991)



[Table 6] Diffusion Approximation for short wave radaition Assumption in Diffusion Approximation : $\quad I(\mathbf{x}, \mathbf{r})=U(\mathbf{x})+c F_{j}(\mathbf{x}) r_{j}$ Diffusion Approximation equations :

$$
\begin{aligned}
& \frac{\partial}{\partial x_{j}}\left[\frac{c_{j}(\mathbf{x})}{a(\mathbf{x})} \frac{\partial U(\mathbf{x})}{\partial x_{j}}\right]-\gamma_{0}(\mathbf{x}) a(\mathbf{x}) U(\mathbf{x})=\frac{\partial d_{j}(\mathbf{x}) E_{j}(\mathbf{x})}{\partial x_{j}}-a(\mathbf{x}) E(\mathbf{x}) \\
& F_{\alpha}(\mathbf{x})=-\frac{c_{\alpha}(\mathbf{x})}{a(\mathbf{x})} \frac{\partial U(\mathbf{x})}{\partial x_{\alpha}}+d_{\alpha}(\mathbf{x}) E_{\alpha \alpha}(\mathbf{x}) \\
& E(\mathbf{x})=\int_{\omega=4 \pi} e(\mathbf{x}, \mathbf{r}) d \omega=\int_{\omega^{\prime}=4 \pi, \omega=4 \pi} \iint_{n} \Gamma\left(\mathbf{x}, \mathbf{r}, \mathbf{r}^{\prime}\right) i_{d}\left(\mathbf{x}, \mathbf{r}^{\prime}\right) d \omega d \omega^{\prime} \\
& E_{l}(\mathbf{x})=\int_{\omega=4 \pi} e(\mathbf{x}, \mathbf{r}) r_{l} d \omega=\int_{\omega^{\prime}=4 \pi, \omega=4 \pi} \iint_{1} r(\mathbf{r}, \mathbf{r}) i_{d}\left(\mathbf{x}, \mathbf{r}^{\prime}\right) r_{l} d \omega d \omega^{\prime} \\
& \text { Boundary Condition : } \quad \frac{c_{j}}{a} \frac{\partial U}{\partial x_{j}} n_{j}=2 \pi U+d_{j} E_{j} n_{j} \\
& \gamma_{0}(\mathbf{x})=\alpha_{0}-\beta_{0}(\mathbf{x}), \quad c_{j}(\mathbf{x})=\frac{1}{c \chi_{j}(\mathbf{x})}, \quad d_{j}(\mathbf{x})=\frac{1}{\chi_{j}(\mathbf{x})}, \quad \chi_{\alpha}(\mathbf{x})=\left(\alpha_{\alpha \alpha \underline{\alpha}}(\mathbf{x})-\beta_{\alpha \alpha}^{*}(\mathbf{x})\right) c \\
& \left.\alpha_{0}=\int_{\omega=4 \pi} G(\mathbf{x}, \mathbf{r}) d \omega=2 \pi, \quad \beta_{0}(\mathbf{x})=\int_{\omega=4 \pi, \omega^{\prime}=4 \pi} \iint_{(\mathbf{x}} \Gamma, \mathbf{r}, \mathbf{r}^{\prime}\right) d \omega d \omega^{\prime} \\
& \alpha_{\alpha \alpha}(\mathbf{x})=\int_{\omega=4 \pi} G(\mathbf{x}, \mathbf{r}) r_{\alpha} r_{\alpha} d \omega, \quad \beta_{\alpha \alpha}(\mathbf{x})=\iint_{\omega=4 \pi, \omega^{\prime}=4 \pi} \Gamma\left(\mathbf{x}, \mathbf{r}, \mathbf{r}^{\prime}\right) r_{\alpha} r_{\alpha}^{\prime} d \omega d \omega^{\prime}, c=\frac{3}{4 \pi}
\end{aligned}
$$

[Table 7] Diffusion Approximation for long wave radiation Assumption in Diffusion Approximation: $\quad i(\mathbf{x}, \mathbf{r})=U(\mathbf{x})+c F_{j}(\mathbf{x}) r_{j}$ Diffusion Approximation equations :

$$
\begin{array}{cc}
\frac{\partial}{\partial x_{j}}\left[\frac{c_{j}(\mathbf{x})}{a(\mathbf{x})} \frac{\partial U(\mathbf{x})}{\partial x_{j}}\right]-\gamma_{\mathrm{c}} a(\mathbf{x}) U(\mathbf{x})=-a(\mathbf{x}) E(\mathbf{x}) \quad(2), \quad & F_{\alpha}(\mathbf{x})=-\frac{c_{\alpha \alpha}(\mathbf{x})}{a(\mathbf{x})} \frac{\partial U(\mathbf{x})}{\partial x_{\alpha}} \\
E(\mathbf{x})=\int_{\omega=4 \pi} e(x, r) d \omega=\alpha_{0} \frac{\varepsilon(x)}{\pi} \sigma\left(T_{i}(x)+273.15\right)^{4} & (4), \quad c=\frac{3}{4 \pi}
\end{array}
$$

Boundary Condition

$$
\frac{c_{j}}{a} \frac{\partial U}{\partial x_{j}} n_{j}=2 \pi\left(U-\bar{i}_{o u l}\right)
$$

$\bar{i}_{\text {out }}=\frac{1}{\pi} \int_{\omega=2 \pi} i_{\text {out }}(\mathbf{r})|-(\mathbf{r} \cdot \mathbf{n})| d \omega, \quad \gamma_{0}(\mathbf{x})=\alpha_{0}-\beta_{0}(\mathbf{x}), \quad c_{j}(\mathbf{x})=1 /\left(c \chi_{j}(\mathbf{x})\right)$,

$\chi_{\alpha}(x)=\left[\alpha_{\alpha \alpha}(\mathbf{x})-{ }^{*} \beta_{\alpha \alpha}(\mathbf{x})\right] c, \quad \alpha_{0}=\int_{\omega=4 \pi} G(\mathbf{x}, \mathbf{r}) d \omega=2 \pi, \alpha_{\alpha \alpha}(\mathbf{x})=\int_{\omega=4 \pi} G(\mathbf{x}, \mathbf{r}) r_{\alpha} r_{\alpha} d \omega$

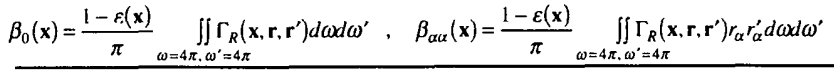


つて計算した。

\section{2 放射計算の条件}

太陽高度は 60 度、 $\mathrm{x}$ 軸方向に入射するものとした。直達日射量、 拡散日射量の算出は文献いに従った。晴天日を想定し、大気透過 率は 0.8 とした。湿度 $40 \%$ 、気温 20 度として、天空長波放射量を文 献12) (4.83)式から求めた。地面のアルべドは 0 、射出率は 1 とした。

単一葉の日射透過率は、0.1(PAR)、0.5(NIR)、反射率は、0.1(PAR)、 0.4(NIR)とした。射出率は 0.9 とした。これらの值は葉の持つ典型的 な值である。PAR conversion factor（PAR／短波放射量）は、太陽高 度 60 度のとき、0.425（直達日射）、0.7 (拡散日射) とした(これ らの值は Ross によって測定された、文献4) 参照)。葉の配置関数 $\left(g\left(\mathbf{x}, \mathbf{r}_{L}\right)\right)$ は uniform 型 $\left(g\left(\mathbf{r}_{L}\right)=1\right)$ を取り上げた。

\section{3 気流計算の条件}

1) 流入境界（ $\mathrm{x}=0$ の $\mathrm{y}-\mathrm{z}$ 平面）: 粗度 $z_{0}=1[\mathrm{~cm}]$,

$$
\begin{aligned}
& U(z)=\left(u_{*} / \kappa\right) \log \left(z / z_{0}\right), \quad k=u_{*}^{2} / \sqrt{C_{D}}, \quad \varepsilon(z)=u_{*}^{3} /(\kappa z), \\
& U(30 m)=2[\mathrm{~m} / \mathrm{s}], \quad \Theta=20[\mathrm{C}], \quad q=5.82[\mathrm{~g} / \mathrm{Kg}],
\end{aligned}
$$$$
C=13.9\left[\mathrm{mmol} / \mathrm{m}^{3}\right] \text {, とした。他の成分は } 0 \text { 。 }
$$

2) 上端境界条件 $(\mathrm{z}=30 \mathrm{~m}): \quad U=2, V=0, \Theta=20$, $q=5.82, \quad C=13.9, \quad \partial W / \partial z=0, \quad \partial k / \partial z=0$, $\partial \varepsilon / \partial z=0, \quad$ とした。

3) 地面境界条件： 風速は対数則、 $\Theta=20, q=5.82$, $C=13.9, \partial k / \partial z=0, \varepsilon\left(z_{1}\right)=C_{D}^{3 / 4} k_{1}^{3 / 2} /\left(\kappa z_{1}\right)$, とした。

4) 流出境界条件 ( $x=48 \mathrm{~m}$ の $\mathrm{y}-\mathrm{z}$ 平面)：全ての変数に対して $\mathrm{x}$ 方向の微分が 0 とした。

5) 側面境界条件 ( $\mathrm{y}=0, \mathrm{y}=30 \mathrm{~m}$ の $\mathrm{x}-\mathrm{z}$ 平面): $V=0$, 他の変数 はy方向の微分が 0 とした。

6) 葉群の抵抗係数 $\left(c_{f}\right)$ : 大橋らの実験に従い、 $c_{f}=0.275$ と した。一般に、 $c_{f}=0.2 \sim 0.3$ の值である。

\section{4 気孔コンダクタンス計算の条件}

Collatz らの気孔コンダクタンスモデルに入れるパラメータ值は、 現時点では Collatz らが行った奉験データしかない。従って、今回は Collatz らパラメータ值（文献6)）をそのまま用いた。Collatz らのモ デルは $\mathrm{C}_{3}$ 植物の光合成のメカニズムを考慮したモデルであるため、 樹木の葉にこれらの数值を入れても定性的には妥当と考えられる。

\section{5 計算結果}

以下に示寸計算結果は全て、 $y=15 \mathrm{~m}$ での $\mathrm{x}-\mathrm{z}$ 断面（樹木の中心） の結果を図示する。

\section{(1) 周囲空気について}

Fig. 1 に風速べクトルを示す。樹木の下流に大きな伴流域が発生 しているのがわかる。建物の伴流域と異なり、この伴流域では逆流 は生じていない。単なる風速の減衰となっている。（固定した）渦 は発生していない。Fig. 2 に気温の分布を示す。樹木の内部と風下 側に気温の低い部分が広がっている。これは、空気が樹木を通過す る際に、葉からの蒸散によって冷却され、移流により後流に流され
たためである。Fig. 3 に比湿の分布を示す。樹木の内部之風下側に 高い比湿の領域が広がっている。この現象は、気温の場合と同様に、 葉の蒸散と移流に因る。Fig. 4 に二酸化炭素濃度 (mole fraction) の 分布を示す。二酸化炭素の場合も、気温や比湿と同様に、伴流域に 低い濃度部分が生じている。この現象は、葉の光合成による空気中 の二酸化炭素の固定と移流に因る。

(2) 葉群内のエネルギー収支について

Fig. 5 から Fig. 10 に樹木内の熱収支の詳細を示す。Fig. 5 は葉群 に吸収されるPAR の分布を示す。Fig. 6 は葉群に吸収される NIRの 分布である。Fig. 7 は樹木内の正味の長波放射量（負值は葉からの 射出を示す）の分布を示す。Fig. 5 から光合成に影響を及ほす PAR は直達日射を受ける樹木の上面と前面付近で強く吸収されている。 一方、NIR は PAR に比べて樹木の内部深くまで浸透している。この 差は、単一葉のPAR に対する強い吸収性と、NIRに対する強い散乱 性状に起因する。正味の長波放射量は樹木の上端で強く射出する。 この原因は、大気放射が、地面や葉の放射に比べて小さいためであ る。正味の長波放射量は葉群に吸収される NIR と同じオーダーであ る。このことから、長波放射を簡易に取り扱うと樹木内の熱収支の 子測に大きな䛊差を生じさせる危険性があることが推定される。

Fig. 8 は蒸散による潜熱を示す。Fig. 9 は乾燥空気による顕熱を示 す（正值は葉からの放熱を示す)。Fig. 10 は蒸散によって葉から放 出される水蒸気の顕熱を示す。Fig. 8 から、葉によって吸収される 日射量の大部分が蒸散による潜熱によって放出されることが分る。 顕熱によるエネルギーの放出は潜熱による放出に比べて小さい。Fig. 9 と Fig. 10 から、水蒸気による顕熱は乾燥架気による顕熱に比べて $10^{-2}$ のオーダー小さく、無視し得ることが分る。

（3）蒸散速度、正味の二酸化炭素固定速度の詳細

Fig. 11 に蒸散速度の分布を示す。Fig. 12 は正味の二酸化炭素固定 速度である。Fig. 13 は気孔コンダクタンスの分布である。蒸散速度 と正味の二酸化炭素固定速度は樹木の上端部と前面部で大きくなっ ている。この領域は PAR が葉によって強く吸収される部分とほほ一 致している。気孔コンダクタンスの分布は、基本的には蒸散速度や 正味の二酸化炭素固定速度の分布と一致しているが、樹木の後方上 端部で大きな值を示している。風速などの気孔コンダクタンス以外 の環境因子も樹木の熱収支に相互的に影響を与えるが、気孔コンダ クタンスが樹木の熱収支に大きな影響を与えていることは、Fig. 13 から明らかである。Fig. 14 は葉温の分布を示す。葉温は樹木の前面 下部で高く、後部下部で低くなっている。この現象は、前面下部で は直達日射を受け、かつ、長波放射の射出が小さいこと、樹木後部 下部では、気温が低く、かつ、吸収される日射量も小さいことが、 この原因となっている。

\section{4. まとめと今後の課題}

樹木内の熱・水分·二酸化炭素収支を予測するモデルを用いて、 シミュレイションを行った。以下の点が明らかになった。

1) 低温、高湿度、低二酸化炭素濃度の領域が樹木下流の伴流域に見 いだされた。一方、蒸散速度と光合成速度は、直達日射を受け る樹木の前面と上端部で強くなっていた。

2）葉によって吸収される日射量の大部分が蒸散により放熱される。

3）長波放射のエネルギー収支への影響は無視しえない。 


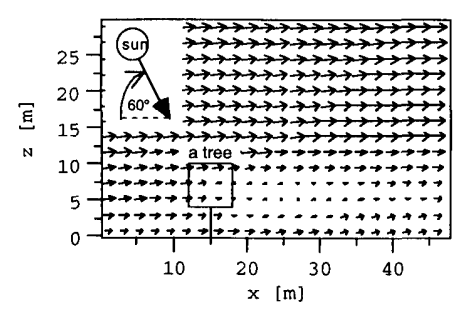

$\rightarrow=2.000 \mathrm{e}+00$

Fig. 1 Wind velocity vectors
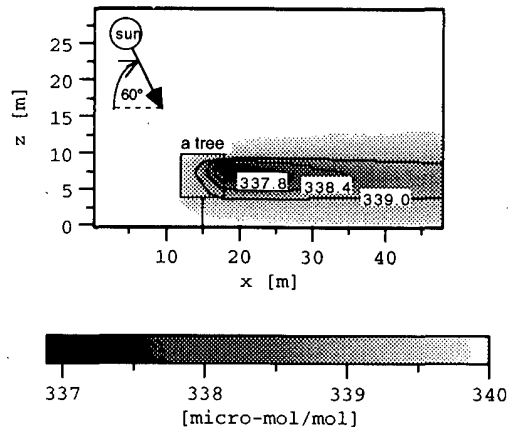

Fig. 4 Distribution of $\mathrm{CO}_{2}$ mole fraction

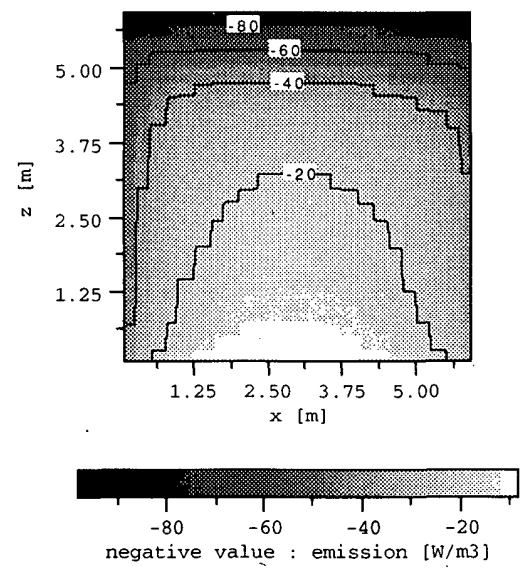

Fig. 7 Net long wave radiation within foliage

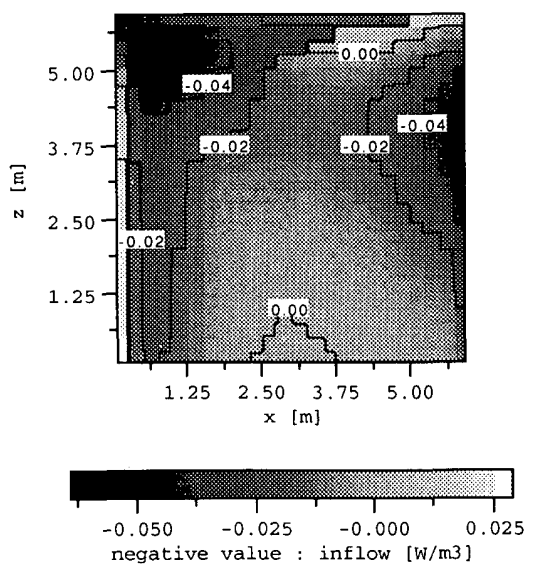

Fig. 10 Distribution of vapor sensible heat
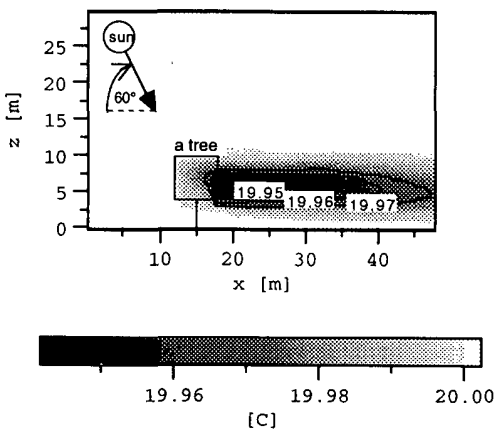

Fig. 2 Distribution of air temperature

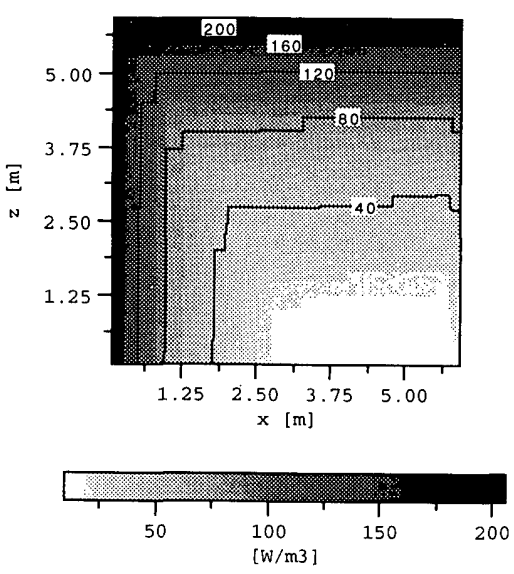

Fig. 5 PAR absorbed by leaves


Fig. 8 Distribution of latent heat

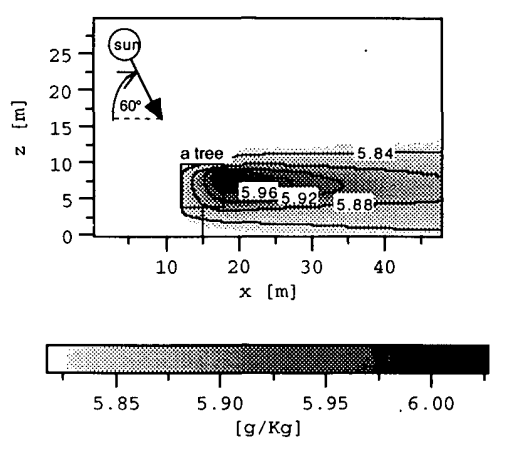

Fig. 3 Distribution of specific humidity
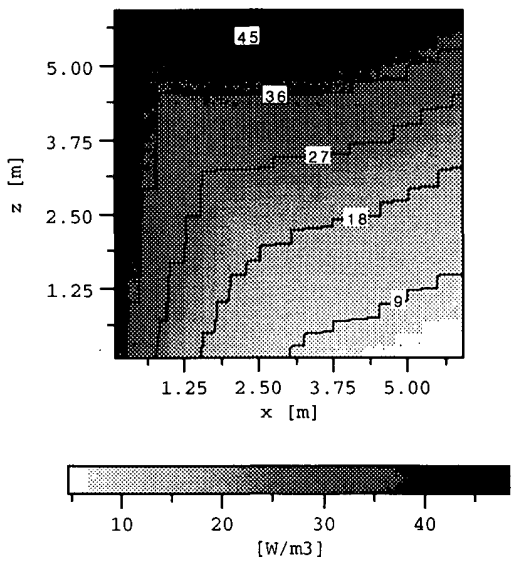

Fig. 6 NIR absorbed by leaves
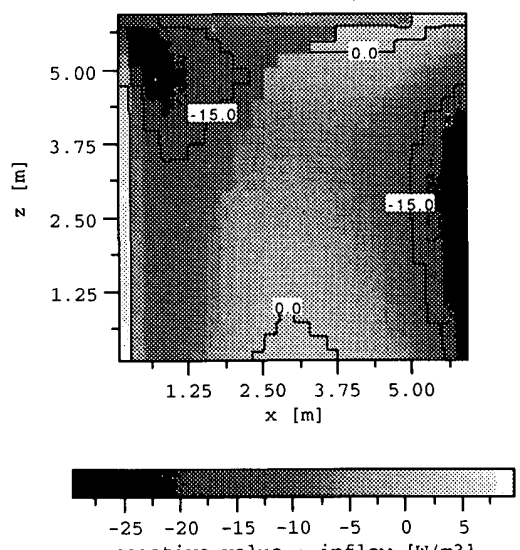

negative value : inflow $[\mathrm{W} / \mathrm{m} 3]$

Fig. 9 Distribution of dry air sensible heat

4) 蒸散による葉からの水蒸気の流入による水蒸気の顕熱による熱交 換は、乾燥空気による葉面と周囲空気との顕熱交換に比べ、無 視しえる。

本研究で用いたサブモデルに対しては、個々に検証されている。 乱流モデルに関しては、文献 ${ }^{2}$ )，9)により、Ross の放射輸送モデル に関しては、文献14)，15)により、気孔コンダクタンスモデルに関


文献16)により検証されている。従って、今回計算した結果は、定 性的には信頼できる。しかし、本研究で行った計算は同一の植物の パラメータを用いて計算したものではない。今後の課題として、同 一の植物のパラメータを用いた計算と実測との比較が必要である。 




Fig. 11 Transpiration rate within foliage

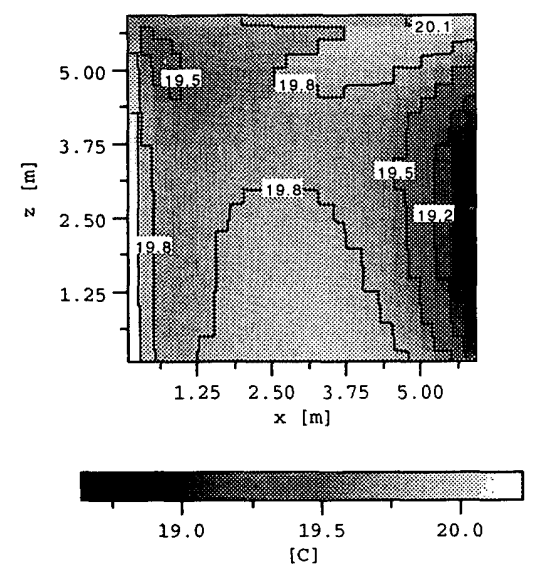

Fig. 14 Distribution of leaf temperature

\section{[Appendix-1] 植栽内空気相の連続の式の導出}

空気相の質量保存式(瞬時値)は次式で表される。

$$
\frac{\partial \tilde{\rho}}{\partial t}+\frac{\partial \tilde{\rho} \tilde{u}_{j}}{\partial x_{j}}=0
$$

文献1，31，注31に従って、上式をアンサンブル平均し、次に空気相 に関して空間平均すると次式となる。

$$
\begin{aligned}
& \frac{\partial\langle\bar{\rho}\rangle}{\partial t}-\frac{1}{V_{0}} \int_{\text {leaf }} H\left(\mathrm{x}-\mathrm{x}^{\prime}\right) \bar{\rho}\left(\mathbf{x}^{\prime}\right) \bar{v}\left(\mathbf{x}^{\prime}\right) n_{j}^{\prime} d s\left(\mathbf{x}^{\prime}\right) \\
& +\frac{\partial\left\langle\overline{\rho u_{j}}\right\rangle}{\partial x_{j}}+\frac{1}{V_{0}} \int_{\text {Leaf }} H\left(\mathbf{x}-\mathbf{x}^{\prime}\right) \overline{\rho\left(\mathbf{x}^{\prime}\right) u_{j}\left(\mathbf{x}^{\prime}\right)} n_{j}^{\prime} d s\left(\mathbf{x}^{\prime}\right)=0
\end{aligned}
$$

葉は体積を持たないと仮定すると、葉の両面の速度 $\left(\bar{v}\left(\mathrm{x}^{\prime}\right)\right)$ は等 しいから、

$$
\frac{1}{V_{0}} \int_{\text {leaf }} H\left(\mathbf{x}-\mathbf{x}^{\prime}\right) \bar{\rho}\left(\mathbf{x}^{\prime}\right) \bar{v}\left(\mathbf{x}^{\prime}\right) n_{j}^{\prime} d s\left(\mathbf{x}^{\prime}\right)=0
$$

また、空間微分に関する葉面での表面積項は次式で表される。

$-\frac{1}{V_{0}} \int_{\text {Leaf }} H\left(\mathbf{x}-\mathbf{x}^{\prime}\right) \overline{\rho\left(\mathbf{x}^{\prime}\right) u_{j}\left(\mathbf{x}^{\prime}\right)} n_{j}^{\prime} d s\left(\mathbf{x}^{\prime}\right)=a\left(\hat{S}_{v a p}+\hat{S}_{O 2}-\hat{S}_{C O 2}\right)$

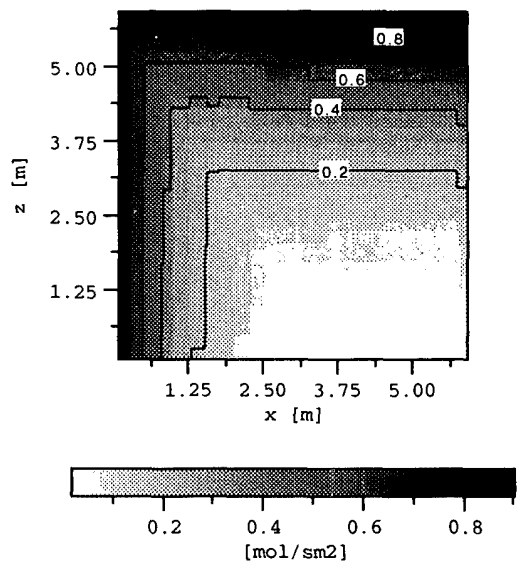

Fig. 13 Stomatal conductance within foliage
ここで、 $a=$ leaf $/ V_{0}$ （葉面積密度）、 $\hat{S}_{v a p}=0.018 E$,

$\hat{S}_{O 2}=0.032 A_{n}, \quad \hat{S}_{C O 2}=0.044 A_{n}$ 。

$\rho=\rho_{a}(1+q),|q|<<1$ だから、 $\rho \approx$ const と近似すると、 次の連続の式が得られる。

$$
\begin{gathered}
\frac{\partial\left\langle\bar{u}_{j}\right\rangle}{\partial x_{j}}=S_{v a p}+S_{O 2}-S_{C O 2} \\
\text { ここで、 } S_{v a p}=a \hat{S}_{v a p} / \rho, \quad S_{O 2}=a \hat{S}_{O 2} / \rho, \quad S_{C O 2}=a \hat{S}_{C O 2} / \rho 。
\end{gathered}
$$

[Appendix-2] 植栽内の湿潤空気の温度方程式の導出（文献 17) 参照） 水蒸気の質量保存式をモル濃度 $c^{v}$ と水蒸気の速度 $u_{i}^{v}$ で表すと、 次式となる。

$$
\frac{\partial c^{v}}{\partial t}+\frac{\partial c^{v} u_{j}^{v}}{\partial x_{j}}=0
$$

エネルギー保存式をモルエンタルピーで表すと、次式となる。

$$
\begin{aligned}
& \frac{\partial}{\partial t}\left(c^{a} \hat{H}^{a}+c^{v} \hat{H}^{v}\right)+\frac{\partial}{\partial x_{j}}\left(c^{a} \hat{H}^{a} u_{j}^{a}+c^{v} \hat{H}^{v} u_{j}^{v}\right)=\kappa \frac{\partial^{2} \theta}{\partial x_{j}^{2}} \\
& +\frac{D \tilde{p}}{D t}-\tau_{i j} \frac{\partial u_{i}}{\partial x_{j}}+\left[\rho^{a}\left(u_{j}^{a}-u_{j}\right) g_{j}+\rho^{v}\left(u_{j}^{v}-u_{j}\right) g_{j}\right]
\end{aligned}
$$

ここで、 $\hat{H}^{a}$ は乾燥空気 $\left(\mathrm{CO}_{2}\right.$ を含む) のモルエンタルピー、 $c^{a}$ は乾燥空気のモル濃度、 $\hat{H}^{v}$ は水蒸気のモルエンタルピー、 $\theta$ は気 温、 $u_{i}^{a}$ は乾燥空気の速度、 $\tilde{p}$ は絶対圧を示す。

文献１）によれば、流体の速度が音速にくらべて小さい場合、運 動の結果生ずる圧力の変化は、他の熱力学的諸量の変化に比べて小 さいことが記述されている。このことは、次のようにも解釈できる。 
即ち、(2)式左辺と右辺第 1 項が温度に関係する項であり、右辺第 2 、

3、4 項が運動の結果生じる項である。従って、オーダー比較をす れば、 $O\left(\frac{D \tilde{p}}{D t}\right) \approx O\left(-\tau_{i j} \frac{\partial u_{i}}{\partial x_{j}}\right)$ と考えられる。右辺第 3 項は粘性 による運動エネルギーの熱エネルギーへの变換を示す。この項は温 度変化に関係する項に比べて小さいため、(2)式では省略できる。従 って、压力変化項も省略できる。水蒸気のモル濃度が小さいため、 $u_{i}^{v} \approx u_{i}^{a} \approx u_{i}$ と見做せるから、(2)式右辺第 4 項も省略できる。

(2)式を積分表現すれば、次式となる。

$$
\begin{gathered}
\int_{V} \frac{\partial}{\partial t}\left(c^{a} \hat{H}^{a}+c^{v} \hat{H}^{v}\right) d V+\int_{S-l e a f}\left(c^{a} \hat{H}^{a} u_{j}^{a}+c^{v} \hat{H}^{v} u_{j}^{v}\right) n_{j} d S \\
\quad+\int_{\text {leaf }}\left(c^{a} \hat{H}^{a} u_{j}^{a}+c^{v} \hat{H}^{v} u_{j}^{v}\right) n_{j} d S \\
\quad=\int_{S-\text { leaf }} \kappa \frac{\partial \theta}{\partial x_{j}} n_{j} d S+\int_{\text {leaf }} \kappa \frac{\partial \theta}{\partial x_{j}} n_{j} d S
\end{gathered}
$$

次に、水蒸気のモルエンタルピー $(\hat{H})$ を蒸発エンタルピー $\left(l_{v}\right)$ と温度に依存する項 $\left(\hat{H}_{\theta}^{v}\right)$ に分離して、上式を書き直す。

$$
\begin{aligned}
& \int_{V} \frac{\partial}{\partial t}\left(c^{a} \hat{H}^{a}\right) d V+\int_{S-l e a f} c^{a} \hat{H}^{a} u_{j}^{a} n_{j} d S+\int_{\text {leaf }} c^{a} \hat{H}^{a} u_{j}^{a} n_{j} d S \\
& +\int_{V} \frac{\partial}{\partial t}\left(c^{v} \hat{H}_{\theta}^{v}\right) d V+\int_{S-\text { leaf }} c^{v} \hat{H}_{\theta}^{v} u_{j}^{v} n_{j} d S+\int_{\text {leaf }} c^{v} \hat{H}_{\theta}^{v} u_{j}^{v} n_{j} d S
\end{aligned}
$$

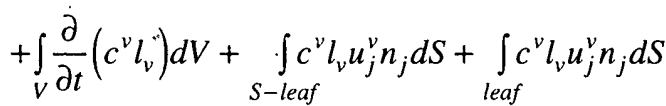

$$
\begin{aligned}
& =\int_{S-l e a f} \kappa \frac{\partial \theta}{\partial x_{j}} n_{j} d S+\int_{\text {leaf }} \kappa \frac{\partial \theta}{\partial x_{j}} n_{j} d S
\end{aligned}
$$

1）式に気化熱 $l_{v}$ （定数）を掛けて積分表示すると、

$$
\int_{V} \frac{\partial}{\partial t}\left(c^{v} l_{v}\right) d V+\int_{S-\text { leaf }} c^{v} l_{v} u_{j}^{v} n_{j} d S+\int_{\text {leaf }} c^{v} l_{v} u_{j}^{v} n_{j} d S=0
$$

であるから、(4)式から気化熱項は消去できて、(3)式は次式となる。

$$
\begin{aligned}
& \int_{V} \frac{\partial}{\partial t}\left(c^{a} \cdot \hat{H}^{a}\right) d V+\int_{S-\text { leaf }} c^{a} \hat{H}^{a} u_{j}^{a} n_{j} d S+\int_{\text {leaf }} c^{a} \hat{H}^{a} u_{j}^{a} n_{j} d S \\
& +\int_{V} \frac{\partial}{\partial t}\left(c^{v} \hat{H}_{\theta}^{v}\right) d V+\int_{S-\text { leaf }} c^{v} \hat{H}_{\theta}^{v} u_{j}^{v} n_{j} d S+\int_{\text {leaf }} c^{v} \hat{H}_{\theta}^{v} u_{j}^{v} n_{j} d S \\
& =\int_{S-\text { leaf }} \kappa \frac{\partial \theta}{\partial x_{j}} n_{j} d S+\int_{\text {leaf }} \kappa \frac{\partial \theta}{\partial x_{j}} n_{j} d S
\end{aligned}
$$

葉面から水蒸気の流入による湿潤空気の温度変化を考えるときは、 (5)式から、水蒸気の気化熱は考慮する必要がないことが分かる。

$-c^{v} u_{j}^{v} n_{j}=E （ E$ は蒸散速度 $\left[\mathrm{mol} /\left(\mathrm{m}^{2} \mathrm{~s}\right)\right] ）$ を考慮すると、

$-\int_{\text {leaf }} c^{v} \hat{H}_{\theta}^{v} u_{j}^{v} n_{j} d S=E \hat{H}_{\theta}^{v} S_{\text {leaf }}=E C_{p}^{v a p o r}\left(\theta_{l}-\theta_{a}\right) S_{\text {leaf }}$

ここで、 $\hat{H}_{\theta}^{v}=C_{p}^{\text {vapor }}\left(\theta_{l}-\theta\right)$ とした。基準温度は周囲空気温度 $\theta$ を用いた。 $\theta_{l}$ は葉温、 $S_{\text {leaf }}$ は葉面積。

$c^{\mathrm{CO} 2} u_{j}^{\mathrm{CO} 2} n_{j}=A_{n} \quad\left(A_{n}\right.$ は正味の $\mathrm{CO}_{2}$ 固定速度 $\left.\left[\mathrm{mol} / \mathrm{m}^{2} \mathrm{~s}\right]\right)$ 、 $-c^{O 2} u_{j}^{O 2} n_{j}=A_{n}$ （C 植物の光合成では、光呼吸を含めた正味の $\mathrm{CO}_{2}$ 固定速度と正味の $\mathrm{O}_{2}$ 放出速度は等しい, 文献8) を考慮すると、 光合成の際の $\mathrm{O}_{2}$ と $\mathrm{CO}_{2}$ によるエネルギー流出入量は次式となる。

$-\int_{\text {leaf }} c^{a} \hat{H}^{a} u_{j}^{a} n_{j} d S=\left(\hat{H}^{O 2}-\hat{H}^{C O 2}\right) A_{n} S_{\text {leaf }}$

$$
=\left[\left(C_{p}^{O 2}-C_{p}^{C O 2}\right)\left(\theta_{l}-\theta\right)\right] A_{n} S_{\text {leaf }}
$$

ここで、 $\hat{H}^{O 2}=C_{p}^{O 2}\left(\theta_{l}-\theta\right) 、 \quad \hat{H}^{C O 2}=C_{p}^{C O 2}\left(\theta_{l}-\theta\right)$ の関係 をもちいた。

顕熱流の項は、葉面の対流熱伝達率 $\left(h_{c}\right)$ を用いて、以下の用に 表される。

$$
\int_{\text {leaf }} \kappa \frac{\partial \theta}{\partial x_{j}} n_{j} d S=2 h_{c}\left(\theta_{l}-\theta\right) S_{l e a f}
$$

以上、(6),(7),(8)式が葉面と周囲空気とのエネルギー交換を示す。気 化熱を考慮する必要はない。但し、 $C_{p}^{\text {vapor }}, C_{p}^{C O 2}, C_{p}^{O 2}$ は、水蒸 気、二酸化炭素、酸素の定圧モル熱容量である。

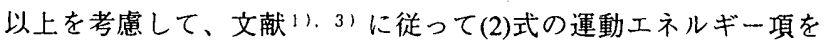
取り除いたエンタルピー式をアンサンブル平均し、空間平均すれば、 植栽内の湿潤空気の温度方程式（Table 1(3)式）が得られる。

[SYMBOLS]

$a:$ leaf area density $\left[\mathrm{m}^{2} / \mathrm{m}^{3}\right]$

$a$ and $b$ : empirical constants, [Table 5]

$A$ : photosynthetic rate $\left[\mathrm{mol} / \mathrm{sm}^{2}\right]$

$A_{n}:$ net photosynthetic rate $\left[\mathrm{mol} / \mathrm{sm}^{2}\right]$

$b$ : empirical constant, [Table 4]

$c_{n}$ : heat capacity of moist air

$c_{p u}$ : specific heat at constant pressure of dry air $c_{p \prime}$ : specific heat at constant pressure of vapor $c_{\mathrm{u}}^{\text {impur }}$ : mole fraction of vapor in ambient air $c_{t}^{\text {wurn }}:$ mole fraction of vapor on leaf surface $c_{a}^{\mathrm{CO} 2}$ : mole fraction of $\mathrm{CO}_{2}$ in ambient air $c_{i}^{c o 2}, c_{i}$ : intercellurar $\mathrm{CO}_{2}$ mole fraction

$c_{s}^{C O 2}, c_{s}$ : mole fraction of $\mathrm{CO}_{2}$ on leaf surface $C$ : mean molar concentration of $\mathrm{CO}_{2}\left[\mathrm{~mol} / \mathrm{m}^{3}\right]$ $C_{p}^{\mathrm{CO} 2}$ : molar heat capacity of $\mathrm{CO}_{2}$ at constant pressure $[\mathrm{W} / \mathrm{molC}]$

$C_{p}^{O 2}$ : molar heat capacity of $\mathrm{O}_{2}$ at constant pressure $[\mathrm{W} / \mathrm{molC}]$

$C_{p}^{\mathrm{utp}}$ : molar heat capacity of vapor at constant pressure $[\mathrm{W} / \mathrm{molC}]$
$H_{O 2}$ : heat exchange of $\mathrm{O}_{2}$ by photosynthesis

$\mathrm{H}_{\mathrm{CO} 2}$ : heat exchange of $\mathrm{CO}_{2}$ by photosynthesis

$i$ : radiance $\left[\mathrm{W} / \mathrm{m}^{2} \mathrm{sr}\right]$

$i_{d}$ : direct component for $i$

$i_{\text {out }}:$ incident radiance (long wave) $\left[\mathrm{W} / \mathrm{m}^{2} \mathrm{sr}\right]$

$1:$ indirect component for $i$

$J_{C}:$ Rubisco-limited rate $\left[\mathrm{mol} / \mathrm{sm}^{2}\right]$

$J_{E}$ : response to $Q_{P_{A R}}\left[\mathrm{~mol} / \mathrm{sm}^{2}\right]$

$J_{s}:$ sucrose synthesis $\left[\mathrm{mol} / \mathrm{sm}^{2}\right]$

$k$ : turbulent energy

$K_{\mathrm{c}}$ : Michaelis constant for $\mathrm{CO}_{2}$, empirical constant

$K_{o}$ : inhibitory constant for $\mathrm{O}_{2}$, empirical constant $l_{\mathrm{v}}$ : heat of vaporization of water $[\mathrm{J} / \mathrm{mol}]$

$m$ : empirical constant, [Table 4]

$n_{i}$ : inward normal unit vector

NIR : Near InraRed radiation

$\left[\mathrm{O}_{2}\right]$ : partial pressure of $\mathrm{O}_{2}[\mathrm{~Pa}]$

$p_{i}$ : partial pressure of intercellular $\mathrm{CO}_{2}[\mathrm{~Pa}]$

$P$ : mean relative pressure 


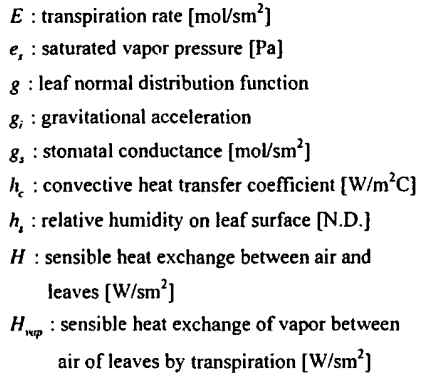





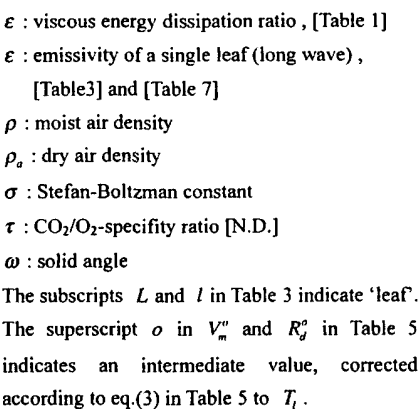

謝辞：Computer time was provided by the Supercomputer Laboratory, Institute of Chemical Research, Kyoto University.

注

注 1）一般に植物の抗力係数は測定から $0.2 \sim 0.3$ となっている。今 回は 0.275 (表 1 ) とした。また、広葉樹の場合、葉面積密 度の平均は1のオーダである。今回は1とした。

注 2 ）前の文献111では、「葉の配置関数は植栽内で一定」と言う もう一つの仮定を設けていた。しかし、この仮定は Ross の放 射輸送方程式の拡散近似式を導出するのに必要なかった。た だし、文献11)の(36)式は、本研究の Table 6の(2)式となる。

注 3 ) 前の文献11では、時間微分項を含んだ関数の空間平均の式の 記述が無かった。空間微分や時間微分項を含んだ関数の正確 な空間平均の式は文献 3 ) 参照。

参考文献

1) 平岡, 丸山, 中村, 桂：植物群落内および都市キャノピー内の乱 流モデルに関する研究，（その1）乱流モデルの作成，日本建 築学会計画系論文報告集, No.406, pp.1-9，1989.12月。

2) 平岡, 丸山, 中村, 桂: 植物群落内および都市キャノピー内の乱 流モデルに関する研究，（その 2）実験デー夕との比較による モデルの検証, 日本建築学会計画系論文報告集, No.416, pp.1-8, 1990.10月.

3) Hiraoka, H.: Modelling of Turbulent Flows within Plant/Urban Canopies, J. Wind Eng. Ind. Aerodyn., vol.46\&47, pp.173-182.

4) Ross, J.: The Radiation Regime and Architecture of Plant Stands, Dr W. Junk, 1981.

5) Ross, J: Radiation Exchange in Plant Canopies, in Heat and Mass Transfer in the Biosphere, I, Transfer Processes in Plant Environment, ed. By de Vries, D.A. and Afgan, N.H., pp.327-336, Scripta Book Co., 1975.

6) Collatz, G.J., Grivet, C., Ball, J.T., and Berry, J.A.: Physiological and Environmental Regulation of Stomatal Conductance, Photosynthesis and Transpiration : a Model that Includes a Laminar Boundary Layer, Agri. Forest Met., vol.54, pp.107-136, 1991.
7) Ball, J.T: An Analysis of Stomatal Conductance, Stanford University, Ph.D thesis, 1988.

8) Farquhar, G.D., von Caemmere, S., and Berry, J.A.: A Biochemical Model of Photosynthetic $\mathrm{CO}_{2}$ Assimilation in Leaves of $\mathrm{C}_{3}$ Species, Planta, vol.149, pp.255-267, 1980.

9) 大橋，神山，成田：樹木の抵抗係数に関する風洞実験，その 4 , 乱流モデルの比較, 日本建築学会大会学術講演梗概集 (東北), 環 境工学 D II, pp.669-670, 2000 .

10) Ishimaru, A.: Wave Propagation and Scattering in Random Media, vol.1, Academic Press., 1978.

11）平岡：Ross の植物群落内放射輸送方程式の拡散近似解法に関す る研究, 日本建築学会計画系論文集, No.495, pp.31-36, 1997.5月.

12）日本建築学会 (編): 建築資料集成 1 環境, 丸善, 1978 .

13）近藤 (編著)：水摆境の気象学, 朝倉書店, 1994.

14）平岡, 中村：Ross, J.の植物群落内放射輸送モデルに関する研究, (その 1) Szeicz, C.の測定データとの比較, 日本建築学会計画系 論文報告集, No.416,pp.17-24，1990.10月.

15) 平凧闺，中村：Ross, J.の植物群落内放射輸送モデルに関する研究, (その 2 ) Ranson, K.J.の測定デー夕との比較, 日本建築学会計画 系論文報告集, No.443, pp.1-6, 1993.1月.

16) 平岡: Ross の植物群落内放射輸送方程式の拡散近似解法の予測 精度の検討，日本建築学会計画系論文報告集，No.512，pp.9-15， 1998.10月.

17) Bird, R.B., Stewart, W.E., and Lightfoot, E.N.: Transport Phenomena, John Wiley \& Sons, Inc., 1960.

18）ランダウ, リフシッッ： 流体力学, 東京図書, 1970.

19) Daudet, F.A., Silverstre, J., Ferreira, M.I., Valancogne, C., and Pradelle, F.: Leaf Boundary Layer Conductance in a Vineyard in Portugal, Agri. Forest Met., vol.89, pp.255-267.

(2000年 8 月 28 日原稿受理， 2001 年 3 月 8 日採用決定） 